\title{
Fluid management in patients undergoing cardiac surgery: effects of an acetate- versus lactate-buffered balanced infusion solution on hemodynamic stability (HEMACETAT)
}

\author{
Carmen A. Pfortmueller ${ }^{1 *}$ (D), Livia Faeh ${ }^{1}$, Martin Müller ${ }^{2,3}$, Balthasar Eberle ${ }^{4}$, Hansjörg Jenni $^{5}$, Björn Zante ${ }^{1}$ \\ Josef Prazak ${ }^{1}$, Lars Englberger ${ }^{5}$, Jukka Takala ${ }^{1}$ and Stephan M. Jakob ${ }^{1}$
}

\begin{abstract}
Background: Recent evidence suggests that acetate-buffered infusions result in better hemodynamic stabilization than $0.9 \%$ saline in patients undergoing major surgery. The choice of buffer in balanced crystalloid solutions may modify their hemodynamic effects. We therefore compared the inopressor requirements of Ringer's acetate and lactate for perioperative fluid management in patients undergoing cardiac surgery.

Methods: Using a randomized controlled double-blind design, we compared Ringer's acetate (RA) to Ringer's lactate (RL) with respect to the average rate of inopressor administered until postoperative hemodynamic stabilization was achieved. Secondary outcomes were the cumulative dose of inopressors, the duration of inopressor administration, the total fluid volume administered, and the changes in acid-base homeostasis. Patients undergoing elective valvular cardiac surgery were included. Patients with severe cardiac, renal, or liver disease were excluded from the study.

Results: Seventy-five patients were randomly allocated to the RA arm, 73 to the RL. The hemodynamic profiles were comparable between the groups. The groups did not differ with respect to the average rate of inopressors (RA $2.1 \mathrm{mcg} / \mathrm{kg} / \mathrm{h}, \mathrm{IQR} 0.5-8.1 \mathrm{vs}$. RL $1.7 \mathrm{mcg} / \mathrm{kg} / \mathrm{h}, \mathrm{IQR} 0.7-8.2, p=0.989$ ). Cumulative doses of inopressors and time on individual and combined inopressors did not differ between the groups. No differences were found in acid-base parameters and their evolution over time.
\end{abstract}

Conclusion: In this study, hemodynamic profiles of patients receiving Ringer's lactate and Ringer's acetate were comparable, and the evolution of acid-base parameters was similar. These study findings should be evaluated in larger, multi-center studies.

Trial registration: Clinicaltrials.gov NCT02895659. Registered 16 September 2016.

Keywords: Fluid therapy, Crystalloid solutions, Cardiac surgical procedures, Hemodynamics, Randomized controlled trial, Vasoconstrictor agents, Perioperative period

\footnotetext{
* Correspondence: carmen.pfortmueller@insel.ch

${ }^{1}$ Department of Intensive Care Medicine, Inselspital, Bern University Hospital,

University of Bern, Freiburgstrasse 10, 3010 Bern, Switzerland

Full list of author information is available at the end of the article
}

(c) The Author(s). 2019 Open Access This article is distributed under the terms of the Creative Commons Attribution 4.0 International License (http://creativecommons.org/licenses/by/4.0/), which permits unrestricted use, distribution, and reproduction in any medium, provided you give appropriate credit to the original author(s) and the source, provide a link to the Creative Commons license, and indicate if changes were made. The Creative Commons Public Domain Dedication waiver (http://creativecommons.org/publicdomain/zero/1.0/) applies to the data made available in this article, unless otherwise stated. 


\section{Introduction}

Cardiovascular surgery generates a systemic inflammatory response that increases oxygen consumption and is associated with changes in cardiac output and oxygen delivery [1, 2]. Perioperative hemodynamic support is influenced by the patients' underlying cardiac disease, the complexity of the surgical intervention, the inflammatory response to extracorporeal circulation, and the need for perioperative anticoagulation [3]. Patients often require several hours of postoperative hemodynamic support after cardiac surgery while still sedated and intubated on the intensive care unit (ICU) $[4,5]$, and frequently, they receive a substantial amount of intravenous fluid within a short time period.

Volume replacement strategies and type of fluid used in patients undergoing cardiac surgery have changed over the years [6]. Safety concerns regarding the use of synthetic colloid solutions in cardiac surgery patients $[2,7,8]$ have led to increased use of crystalloid infusions $[6,9,10]$.

Recently, two studies suggested that acetate-buffered crystalloid solutions result in better hemodynamic stabilization than $0.9 \%$ saline in patients undergoing major surgical procedures $[11,12]$. However, the use of acetate-containing balance solutions has been criticized due to the risk of vasodilatation and metabolic alkalosis [13-18]. Patients undergoing cardiac surgery typically require several hours of hemodynamic support, and both acetate-buffered and lactate-buffered crystalloids are used in clinical practice.

We therefore hypothesized that the use of an acetatebased balanced crystalloid solution for perioperative fluid replacement in patients undergoing cardiac surgery would result in a lower average rate of inopressors, a lower cumulative dose of inopressors, a shorter total time on inopressors, and a lesser amount of fluid needed to achieve hemodynamic stability than the use of a lactate-buffered crystalloid solution.

\section{Methods \\ Design}

We conducted a randomized double-blind single-center clinical trial investigating the effect of Ringer's acetate (RA) vs. Ringer's lactate (RL) on hemodynamic stability and fluid requirements in patients undergoing cardiac surgery.

\section{Ethical considerations}

The study was approved by the ethics committee of the Canton of Bern (2016-01039) and was registered in a clinical trial register (NCT02895659). Written preoperative informed consent was obtained from every patient included in the study.

\section{Setting}

The study was conducted between December 1, 2016, and October 19, 2017, in the Department of Intensive Care Medicine of the Inselspital, Bern University Hospital, University of Bern, Bern, Switzerland.

\section{Study endpoints}

The primary endpoint of this study was the average rate of inopressors (norepinephrine and epinephrine) per kilogram body weight-hour until hemodynamic stabilization. Secondary study endpoints were (i) cumulative inopressor dose, (ii) time on inopressors, (iii) cumulative dose of and time on inodilators and vasodilators, (iv) total amount of fluid administered until hemodynamic stabilization, and (v) occurrence of metabolic alkalosis. The study groups were compared with regard to the average rate of inopressor administration, the average rate of norepinephrine and epinephrine administration, the cumulative inopressor dose, the cumulative time on inopressors, the cumulative dose of and time on inodilators and vasodilators, the total amount of fluid administered until hemodynamic stabilization, and the occurrence of metabolic alkalosis. Further, fluid balance, urinary output, and blood loss were defined as outcomes post hoc. Additionally, patient characteristics and postoperative complications were evaluated. Metabolic alkalosis was defined as $\mathrm{pH}$ $>7.45$ and bicarbonate $>26 \mathrm{mmol} / \mathrm{L}$. Alkalemia was defined as $\mathrm{pH}>7.45$.

\section{Time to hemodynamic stabilization: definition of the study period}

We aimed to investigate the perioperative period until achievement of hemodynamic stabilization. The study period commenced with the induction of general anesthesia and ended when hemodynamic stabilization was achieved. This point in clinical recovery was defined in the following way: (a) successful extubation and free from vasoactive support; (b) intubated with inopressor agents, but inopressor dose either weaned entirely or unchanged for $>8 \mathrm{~h}$ or (c) $72 \mathrm{~h}$ after ICU admission. Thereafter, follow-up continued for secondary endpoints for the duration of the hospital stay. The study fluid was not restarted once the initial stabilization was achieved.

The following is the rationale for this definition: the typical hemodynamic problems after cardiac surgery include reduced intravascular blood volume accompanied by peripheral vasoconstriction, low cardiac output (with or without hypotension) due to compromised cardiac function, and/or preload, and major changes in vascular tone $[19,20]$. All these may be augmented due to heart-lung interactions during weaning and due to acute hemodynamic changes related to extubation. Our clinical guidelines recommend extubation as soon as the patient is 
awake and hemodynamically stable. Extubation is usually postponed if the patient needs frequent adjustment of vasoactive drugs and or volume substitution. We therefore took "successful extubation and free from vasoactive drugs" to imply hemodynamic stability and considered patients who remained intubated without hemodynamic support or did not need any change in the hemodynamic management for $>8 \mathrm{~h}$ as stable.

\section{Patients}

A CONSORT flow chart is provided in Fig. 1. Patients were eligible for the study if they were scheduled to undergo an elective open surgical singleor double-valve procedure, combined valve and coronary bypass surgery, or combined valve and proximal aortic surgery.

We included routine cardiac surgery patients with no severe comorbidities. Thus, the exclusion criteria were as follows: age less than 18 or older than 80 years, pre-existing severely impaired cardiac or renal function (EF < 30\%; eGFR < $30 \mathrm{~mL} / \mathrm{min} / 1.73 \mathrm{~m}^{2}$ ), pre-existing anemia necessitating a cardiopulmonary bypass (CPB) circuit prime with red cell concentrate, chronic inflammatory diseases, on long-term steroid medication, chronic liver disease (bilirubin $>3 \mathrm{mg} \cdot \mathrm{dl}^{-1}$ ), active infection or sepsis, emergency or redo surgery, planned use of minimal extracorporeal circuits (MECC) or of early (in the OR) extubation protocols, and patients with restrictions to full therapy. Isolated CABG surgery was excluded since minimized extracorporeal circulation and a fast-track regimen are used in our center for this type of cardiac surgery. This results in considerably less exposure to the intervention (crystalloid load) than the use of conventional $\mathrm{CPB}$ as in valve surgery.

\section{Randomization and material}

Computerized randomization was performed in blocks of 20 patients. Concealment used the opaque sealed envelope method. After informed consent was obtained, patients were randomly allocated to receive either RA (Fresenius $\mathrm{Kabi}^{\ominus}$, Switzerland $\mathrm{GmbH}$; theoretical osmolarity $291 \mathrm{mosml} / \mathrm{kg}$, containing sodium $137 \mathrm{mmol} / \mathrm{L}$, potassium $4.0 \mathrm{mmol} / \mathrm{L}$, chloride $110 \mathrm{mmol} / \mathrm{L}$, calcium $1.65 \mathrm{mmol} / \mathrm{L}$, magnesium $1.25 \mathrm{mmol} / \mathrm{L}$, acetate 36.8 $\mathrm{mmol} / \mathrm{L}$ ) or RL (Fresenius $\mathrm{Kabi}^{\odot}$, Switzerland $\mathrm{GmbH}$; theoretical osmolarity $278 \mathrm{mosm} / \mathrm{L}$, sodium 130.9 $\mathrm{mmol} / \mathrm{L}$, potassium $5.4 \mathrm{mmol} / \mathrm{L}$, chloride $111.7 \mathrm{mmol} / \mathrm{L}$, calcium $1.84 \mathrm{mmol} / \mathrm{L}$, lactate $28.3 \mathrm{mmol} / \mathrm{L}$ ). For each patient, a box with concealed bags of study infusion solution was prepared by a study nurse not involved in the study or patient care and was handed over to both the anesthesiologist and the perfusionist prior to the start of anesthesia. Postoperatively, the box accompanied the patient to the ICU for further study fluid administration until hemodynamic stabilization.

\section{Study conduct}

All patients underwent monitoring of oxygen saturation, heart rate, invasive arterial blood pressure, electrocardiography, respiratory gas analysis, temperature, urine output, central venous pressure, intraoperative transesophageal echocardiography, processed EEG, and postoperative peripheral temperature according to institutional routine. Maintenance of anesthesia, hemodynamic and perfusion management, surgical procedures, and cardiopulmonary bypass weaning were performed according to the departmental standard operating procedures (SOP). All patients were transferred sedated and ventilated from the OR to the ICU.

\section{Hemodynamic management}

Patients received either RL or RA for intravenous fluid resuscitation according to their group allocation. The cardiopulmonary bypass circuit was also exclusively primed with the allocated study fluid. No colloid solutions were used. Hemodynamic and fluid management was guided by TEE and dynamic assessment of both fluid responsiveness and filling pressures, with staged escalation towards vasoactive and/or inotropic and/or mechanical support in case of persistent low cardiac output (mean arterial pressure (MAP) $<60 \mathrm{mmHg}, \mathrm{CCI}<2.2 \mathrm{~L} / \mathrm{min} / \mathrm{m}^{2}, \mathrm{~S}_{\mathrm{mv}} \mathrm{O}_{2}<65 \%$, and/or lactate levels $>2.4 \mathrm{mmol} / \mathrm{L}$ ). The choice of specific agents and interventions was left to the discretion of the attending physician specialists.

Following ICU admission, hemodynamic management [21] was guided using the following targets: MAP 60-90 $\mathrm{mmHg}$, CVP target $<12 \mathrm{mmHg}$, oxygen saturation > $96 \%$, and heart rate $60-110 / \mathrm{min}$. Further, normalization of peripheral temperature, diuresis (target $>0.5 \mathrm{~mL} /$ $\mathrm{kgBW} / \mathrm{h}$ ), and arterial blood lactate concentration $<2.0$ $\mathrm{mmol} / \mathrm{L}$ were expected as the response to treatment. During mechanical ventilation, the pCO2 was kept at < $40 \mathrm{mmHg}$. Since patients after cardiac surgery are vasoconstricted, intravenous fluids were given to restore intravascular volume during vasodilation, to normalize peripheral perfusion, and to allow weaning from vasopressors. If patients were not responding as expected, echocardiography, pulmonary artery catheterization, or both were used to determine the underlying cause. The diagnosis and treatment of specific hemodynamic problems was at the discretion of the intensivist in charge of the patient.

\section{Statistical analysis}

The statistical analysis was performed with Stata $^{\circledR} 13.1$ (StataCorp, College Station, TX, USA). All randomized 


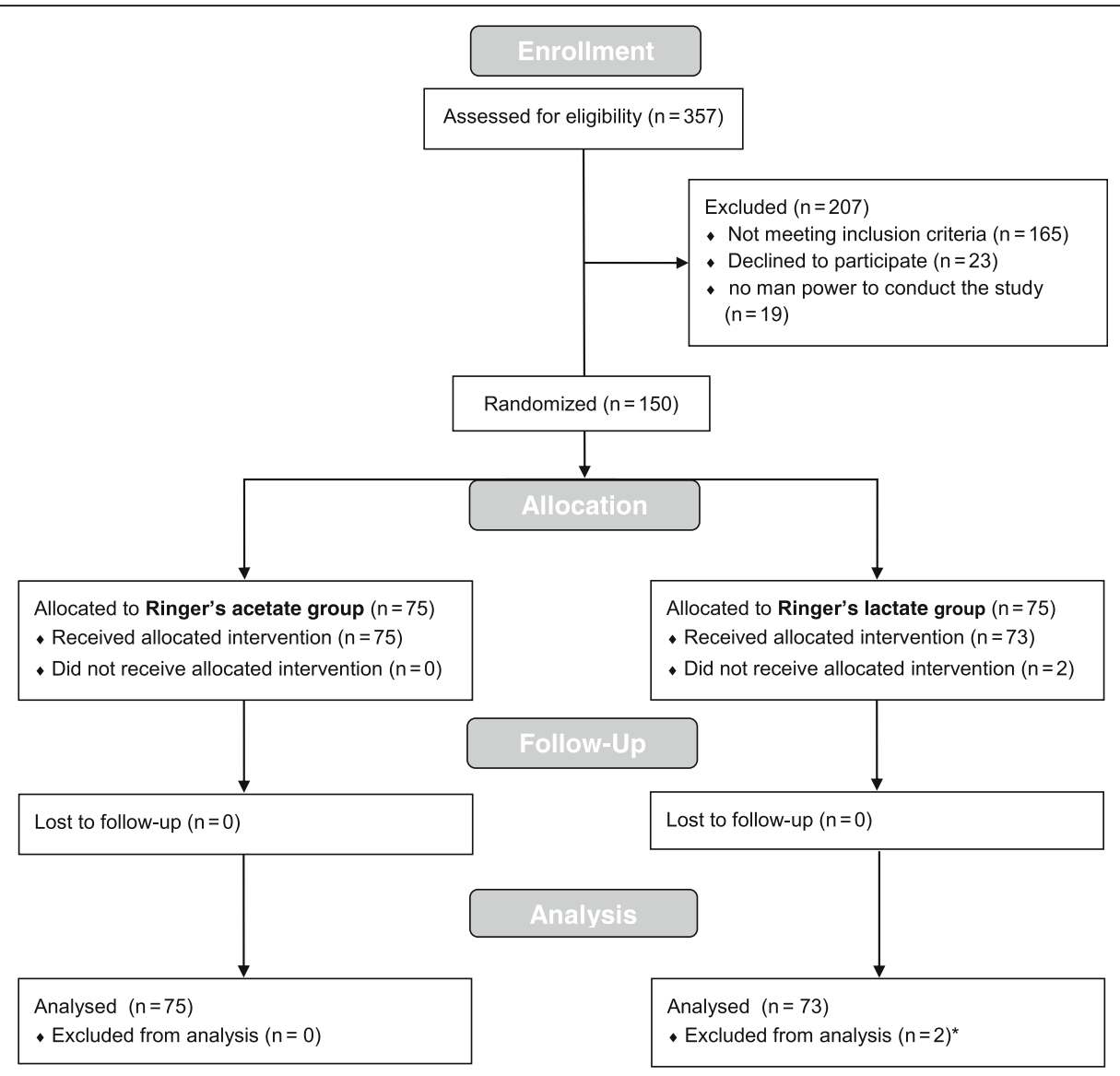

Fig. 1 CONSORT flowchart

patients who received the study fluid were included in the analysis according to a modified intention-to-treat approach [22]. Normal distribution of continuous variables was tested with the Shapiro-Wilk test. Normally distributed variables are presented with mean and standard deviation. Skewed and ordinal variables are presented as medians with interquartile ranges (IQR).

Normally distributed interval and ordinal variables were compared using the unpaired $t$ test and skewed variables using the Wilcoxon rank sum test. Comparisons of categorical variables were performed using the chi-square test or Fisher's exact test, as appropriate [23].

The procedure for analyzing the potential baseline differences between the groups in case of a significant group effect was log-linear regression analysis. All baseline characteristics with a $p$ value of $<0.1$ were included. In addition, further confounders related to increased inopressor use such as aortic insufficiency were also forced into the model. For the purpose of this analysis, skewed outcomes were log-transformed; thus, the exponentiated coefficients correspond to the geometric mean ratio of the outcome.
A mixed restricted cubic spline model was used for the evaluation of changes in hemodynamics and in acidbase homeostasis, i.e., mean arterial pressure, peripheral temperature, urinary output, base access, $\mathrm{pH}$, potassium, and lactate over time between the study groups. Missing values were imputed with the use of the last observation carried forward method for measurements made after baseline.

$p$ values less than 0.05 were considered statistically significant. Figures were drawn using Stata ${ }^{\circ}$.

\section{Results}

Out of 357 screened patients, 150 gave consent and were randomized, and 148 patients actually received the study intervention (see Fig. 1). Seventy-five patients were randomized to the RA group and 73 patients to the RL group. Patients' characteristics are given in Table 1 . In the RL group, more patients underwent a composite graft operation $(n=16,21.9 \%$ vs. $n=4,5.3 \%)$, whereas in the RA group, more patients received a single-valve replacement $(n=59,78.7 \%$ vs. $n=48,65.8 \%)$. The number of patients undergoing 
Table 1 Patient demographics

\begin{tabular}{|c|c|c|c|c|}
\hline Characteristics & Total $(n=148)$ & Ringer's acetate $(n=75)$ & Ringer's lactate $(n=73)$ & $p$ value $^{*}$ \\
\hline \multicolumn{5}{|l|}{ Sex, $n(\%)$} \\
\hline Male & $112(75.7)$ & $56(74.7)$ & $56(76.7)$ & 0.772 \\
\hline Female & $36(24.3)$ & $19(25.3)$ & $17(23.3)$ & \\
\hline Age [years], med (IQR) & $67.5(58.0-72.5)$ & $66.0(58.0-72.0)$ & $68.0(59.0-73.0)$ & 0.631 \\
\hline ASA PS [class], $n(\%)$ & & & & 1.000 \\
\hline 3 & $3(2.0)$ & $2(2.7)$ & $1(1.4)$ & \\
\hline 4 & $145(98.0)$ & $73(97.3)$ & 72 (98.6) & \\
\hline Euroscore, med (IQR) & $18(17-19)$ & $18(17-19)$ & $18(16-19)$ & 0.542 \\
\hline SAPS, med (IQR) & $54(44-62)$ & $54(46-62)$ & $54(42-62)$ & 0.945 \\
\hline NYHA [grade], $n(\%)$ & & & & 0.167 \\
\hline 0 & $11(7.5)$ & $5(6.8)$ & $6(8.2)$ & \\
\hline 1 & $34(23.1)$ & $18(24.3)$ & $16(21.9)$ & \\
\hline 2 & $69(46.9)$ & $34(46.0)$ & $35(48.0)$ & \\
\hline 3 & $28(19.1)$ & $17(23.0)$ & $11(15.1)$ & \\
\hline 4 & $5(3.4)$ & $0(0.0)$ & $5(6.9)$ & \\
\hline Preoperative ejection fraction [\%], med (IQR) & $60(55-65)$ & $60(55-65)$ & $60(55-65)$ & 0.795 \\
\hline Preoperative eGFR [mL/min], med (IQR) & $70(53-85)$ & $73(51-87)$ & $67(54-83)$ & 0.507 \\
\hline \multicolumn{5}{|l|}{ Type of surgery, $n$ (\%) } \\
\hline Composite graft (+valve ${ }^{\#)}$ & $20(13.5)$ & $4(5.3)$ & $16(21.9)$ & 0.004 \\
\hline Other & $128(86.5)$ & $71(94.7)$ & $57(78.1)$ & \\
\hline Single valve & $107(72.3)$ & $59(78.7)$ & $48(65.8)$ & \\
\hline Single valve $+C A B G$ & $12(8.1)$ & $5(6.7)$ & $7(9.6$ & \\
\hline Double valve & $6(4.1)$ & $4(5.3)$ & $2(2.7)$ & \\
\hline Double valve + CABG & $1(0.7)$ & $1(1.3)$ & $0(0.0$ & \\
\hline Triple valve & $2(1.4)$ & $2(2.7)$ & $0(0.0)$ & \\
\hline Duration anesthesia [min], med (IQR) & $310(266-362)$ & $305(266-353)$ & $310(264-364)$ & 0.937 \\
\hline Duration surgery [min], med (IQR) & $202(170-251)$ & $205(176-251)$ & $192(170-264)$ & 0.812 \\
\hline Aortic cross clamp time [min], med (IQR) & $70(56-90)$ & $67(53-86)$ & $73(58-97)$ & 0.172 \\
\hline Hypothermic circulatory arrest n (\%) & $17(11.56)$ & $3(4.00)$ & $14(19.18)$ & 0.004 \\
\hline Red blood cell transfusions [mL], med (IQR) & $340(220-550)$ & $333(223-575)$ & $350(174-550)$ & 0.788 \\
\hline Time until initial hemodynamic stabilization [h], med (IQR) & $12.06(9.7-13.9)$ & $12.08(10.0-13.4)$ & $12.05(9.1-14.1)$ & 0.649 \\
\hline
\end{tabular}

*Wilcoxon rank sum test for continuous variables and chi-square test

${ }^{\circ}$ Fisher's exact test for categorical variables between the Ringer's acetate and the Ringer's lactate study groups including autologous retransfusion and red cell concentrates

\#One patient in the Ringer's lactate group

hypothermic cardiac arrest was also higher in the $\mathrm{RL}$ group $(p=0.004)$. The evolution of blood pressure, peripheral temperature, and urinary output was similar in the Ringer's acetate and the Ringer's lactate groups (Fig. 2).

Primary and secondary study endpoints with respect to the vasoactive medication are given in Additional file 1 and Table 2.

Patients in the RA group did not differ from the RL group with respect to the average rate of inopressors $(2.1 \mathrm{mcg} / \mathrm{kg} / \mathrm{h}, \mathrm{IQR} \quad 0.5-8.1$ and $1.7 \mathrm{mcg} / \mathrm{kg} / \mathrm{h}$, IQR $0.7-8.2$, respectively, $p=0.989$ ). In the log-linear regression model adjusted for the baseline differences between the groups, no significant group effect was found with respect to the primary outcome $(p=$ 0.494). Data on fluids is presented in Table 2. Fluid balance, urinary output, and blood loss did not differ significantly between the groups (data not shown). Changes in acid-base status over time are shown in Fig. 3. No difference in the occurrence of metabolic acidosis $(p=0.327)$ or alkalemia $(p=0.681)$ was noted between the groups. Postoperative outcomes are given in Table 3. Except for the occurrence of postoperative 

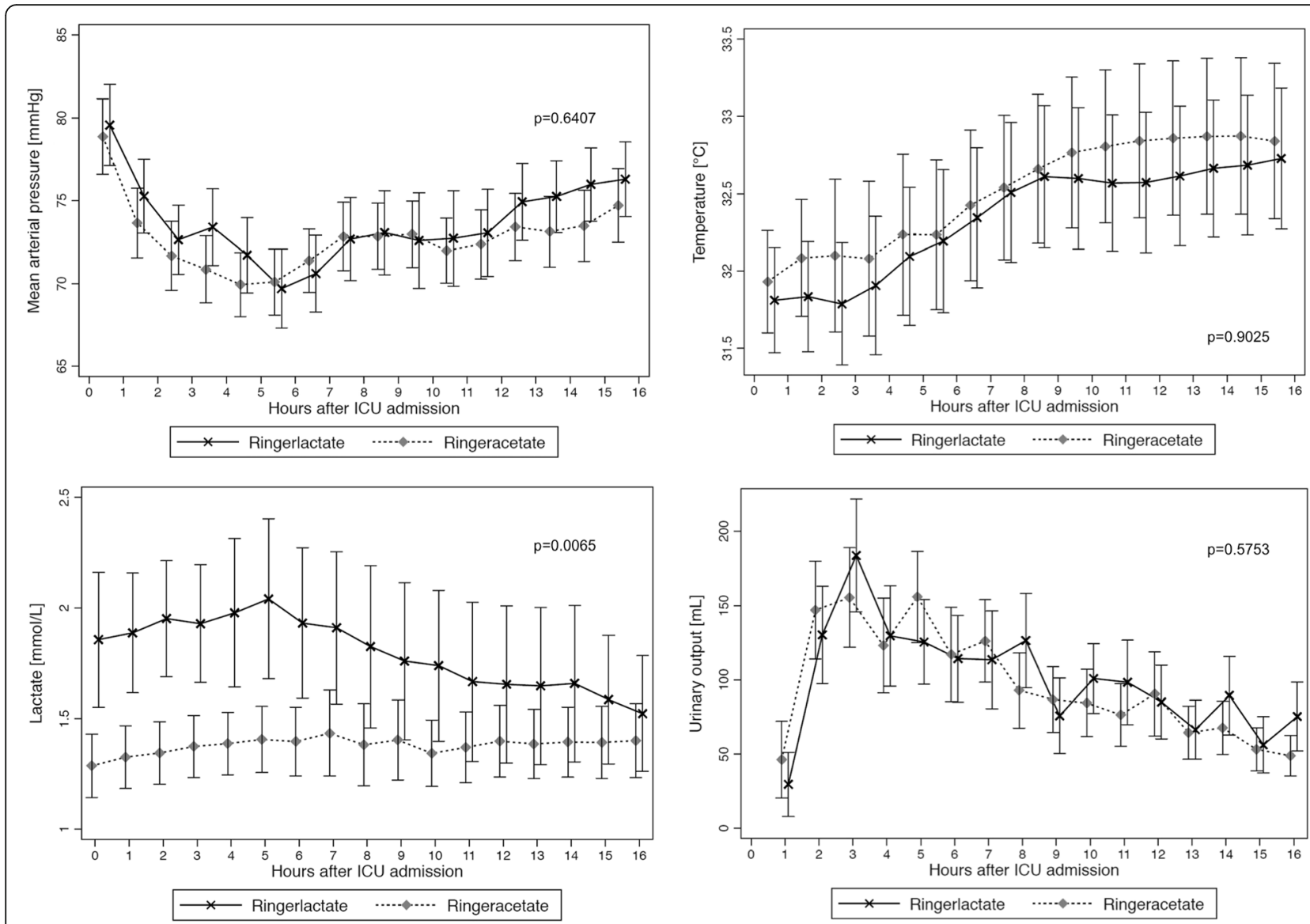

Fig. 2 Hemodynamic profile for the Ringer's acetate and the Ringer's lactate group

arrhythmia $(p=0.008)$, no significant differences in postoperative outcomes were noted $(p$ all $>0.05)$.

\section{Sensitivity analysis: inopressors-norepinephrine and epinephrine}

All patients received norepinephrine infusions $(n=$ $148,100 \%)$, and 41 patients $(27.7 \%)$ received epinephrine infusions at some time during the perioperative period (both $p>0.05$ between the groups). The average norepinephrine rate did not differ between the RA group (median $4.1 \mathrm{mcg} / \mathrm{kg} / \mathrm{h}$, IQR $1.1-11.7$ ) and the RL group (median $3.4 \mathrm{mcg} / \mathrm{kg} / \mathrm{h}$, IQR $1.5-9.5, p$ $=0.907)$. However, patients in the RL group received significantly more epinephrine on average compared to the RA group $(4.5 \mu \mathrm{g} / \mathrm{kg} / \mathrm{h}$, IQR $0.4-33.0$ vs. $0.2 \mu \mathrm{g} / \mathrm{kg} / \mathrm{h}, \mathrm{IQR} 0.1-9.3, p=0.047)$. The significant group effect with regard to the average rate of epinephrine was persistent when using log-linear regression analysis controlled for composite graft operations, deep hypothermic circulatory arrest, and valvular regurgitation (geometric mean ratio 9.9, 95\% CI 1.3, 78.3, $p=0.030)$.
If only the period in the ICU is considered, more patients in the Ringer's lactate group received epinephrine infusions (14 [19.2\%] vs. 6 [8.0\%], $p=0.047)$.

\section{Discussion}

The main finding of this study is that acetate-buffered balanced Ringer's solution does not differ significantly from lactate-buffered Ringer's solution with respect to postoperative hemodynamic stability and phamacological support with inotropic agents in patients scheduled for elective cardiac valve surgery. Also, we observed no difference in the cumulative amount of perioperative i.v. fluids necessary or in acid-base profiles. A small but significant increased average rate of epinephrine was noted in the group with lactate-buffered infusion. The difference in rate was very small, however, and likely of no clinical importance.

Previous observations in humans suggested that the choice of crystalloid fluid might influence the requirements for perioperative vasoactive agents [11, 12, 24]. In these studies, the use of $0.9 \%$ saline was significantly associated with more frequent vasoactive medication when compared to an acetate-buffered infusion group. 
Table 2 Primary and secondary endpoints—vasoactive medication

\begin{tabular}{|c|c|c|c|}
\hline Primary endpoint & $\begin{array}{l}\text { Ringer's acetate }(n=75), \\
\text { median (IQR) }\end{array}$ & $\begin{array}{l}\text { Ringer's lactate }(n=73) \\
\text { median }(I Q R)\end{array}$ & $\begin{array}{l}p \\
\text { value }\end{array}$ \\
\hline $\begin{array}{l}\text { Average rate of inopressors (norepinephrine and epinephrine) }[\mu \mathrm{g} / \mathrm{kg} / \mathrm{h}] \text { until } \\
\text { hemodynamic stabilization }\end{array}$ & $2.1(0.5-8.1)$ & $1.7(0.7-8.2)$ & 0.989 \\
\hline \multicolumn{4}{|l|}{ Secondary endpoints - vasoactive medication } \\
\hline Average rate of norepinephrine $[\mu \mathrm{g} / \mathrm{kg} / \mathrm{h}]$ until hemodynamic stabilization & $1.8(0.5-6.7)$ & $1.5(0.6-4.7)$ & 0.672 \\
\hline Average rate of epinephrine $[\mu \mathrm{g} / \mathrm{kg} / \mathrm{h}]^{\S}$ per hour on epinephrine & $0.2(0.1-9.3)$ & $4.5(0.4-33.0)$ & 0.047 \\
\hline $\begin{array}{l}\text { Average rate of inopressors (norepinephrine and epinephrine) } \\
{[\mu \mathrm{g} / \mathrm{kg} / \mathrm{h}] \text { per hour on inopressors }}\end{array}$ & $4.1(1.0-11.8)$ & $3.7(1.6-12.1)$ & 0.959 \\
\hline Average rate of norepinephrine $[\mathrm{\mu g} / \mathrm{kg} / \mathrm{h}]^{\#}$ per hour on norepinephrine & $4.1(1.1-11.7)$ & $3.4(1.5-9.5)$ & 0.907 \\
\hline Average rate of epinephrine $[\mathrm{\mu g} / \mathrm{kg} / \mathrm{h}]^{\S}$ per hour on epinephrine & $0.2(0.1-9.3)$ & $4.5(0.4-33.0)$ & 0.047 \\
\hline Cumulative dose of inopressors $[\mu \mathrm{g} / \mathrm{kg}]$ & $22(5-83)$ & $20(7-114)$ & 0.928 \\
\hline Cumulative dose of norepinephrine $[\mu \mathrm{g} / \mathrm{kg}]$ & $19(5-71)$ & $16(6-61)$ & 0.726 \\
\hline Cumulative dose of epinephrine $[\mu \mathrm{g} / \mathrm{kg}]$ & $22(5-83)$ & $20(7-114)$ & 0.928 \\
\hline Time on inopressors $[\mathrm{h}]^{\circ}$ & $4.8(4.1-10.7)$ & $6.1(4.0-10.6)$ & 0.505 \\
\hline Time on norepinephrine $[\mathrm{h}]^{\# \circ}$ & $4.8(4.1-6.4)$ & $4.5(3.7-7.4)$ & 0.836 \\
\hline Time on epinephrine $[\mathrm{h}]^{* \circ}$ & $0.0(0.0-0.0)$ & $0.0(0.0-3.4)$ & 0.209 \\
\hline Cumulative dose of inodilators, ICU $[\mu \mathrm{g}]$ & $0(0.0-0.0)$ & $0(0.0-0.0)$ & 0.375 \\
\hline Time on inodilators, ICU [min] & $0(0.0-0.0)$ & $0(0.0-0.0)$ & 0.386 \\
\hline Cumulative dose of vasodilators [mg] & $0(0.0-2.8)$ & $0(0.0-4.2)$ & 0.844 \\
\hline Time on vasodilators, ICU [h] & $0(0.0-1.7)$ & $0(0.0-6.4)$ & 0.726 \\
\hline \multicolumn{4}{|l|}{ Secondary endpoints_fluids } \\
\hline Total amount of study fluid received $(\mathrm{mL})$ & $6677(5325-8479)$ & $6104(4769-7855)$ & 0.272 \\
\hline Total amount of fluid received other than study fluid during study period $(\mathrm{mL})$ & $0(0-0)$ & $0(0-0)$ & 0.976 \\
\hline $\begin{array}{l}\text { Total amount of fluid received after initial hemodynamic stabilization until ICU } \\
\text { discharge }(\mathrm{mL})\end{array}$ & $289(104-972)$ & $255(121-631)$ & 0.711 \\
\hline Total amount of fluid received from the start of anesthesia to ICU discharge $(\mathrm{mL})$ & $7189(5622-9120)$ & $6644(5400-8379)$ & 0.234 \\
\hline
\end{tabular}

This led to the hypothesis that either the high chloride load of $0.9 \%$ saline or the potentially beneficial effects of acetate on the cardiovascular system, seen in the animal model, may be responsible for the difference seen in these studies [12]. Therefore, we designed the current study comparing two chloride-reduced infusion solutions, one of which is acetate-buffered.

Based on our results, we now reject our hypothesis that acetate-buffered Ringer's solution is superior to Ringer's lactate solution with respect to perioperative hemodynamic stability.

The hemodynamic effects of acetate are controversial. Some studies have reported a decline in blood pressure after sodium acetate infusion [25-28], whereas others observed stable $[29,30]$ or even increasing blood pressure [16]. However, most of this evidence originates from the investigations of either sodium acetate infusion or acetate-buffered dialysis, where the acetate load is much higher than in fluid replacement with acetate-buffered Ringer's solution. Therefore, such findings are not generalizable to populations receiving perioperative fluid therapy with acetate-buffered infusions [31]. In fact, the few existing animal and human studies investigating acetate-buffered crystalloid infusions noted potentially beneficial effects on cardiac function [14, 16, 32].

In our study, the hemodynamic profiles of patient groups receiving either RA or RL did not differ significantly, even though large quantities of i.v. fluid were administered. RA therefore appears to be a feasible alternative to RL for fluid resuscitation in the critically ill in terms of hemodynamic effects.

The lack of difference between the two study arms with respect to hemodynamic stabilization in comparison with earlier trials might also be attributed to the reduced chloride load of buffered infusions when compared to saline. Chloride excess was linked to adverse hemodynamic outcomes in several previous human and experimental studies [33-36]. However, the data suggesting that the use of $0.9 \%$ saline leads to hemodynamic effects are limited 

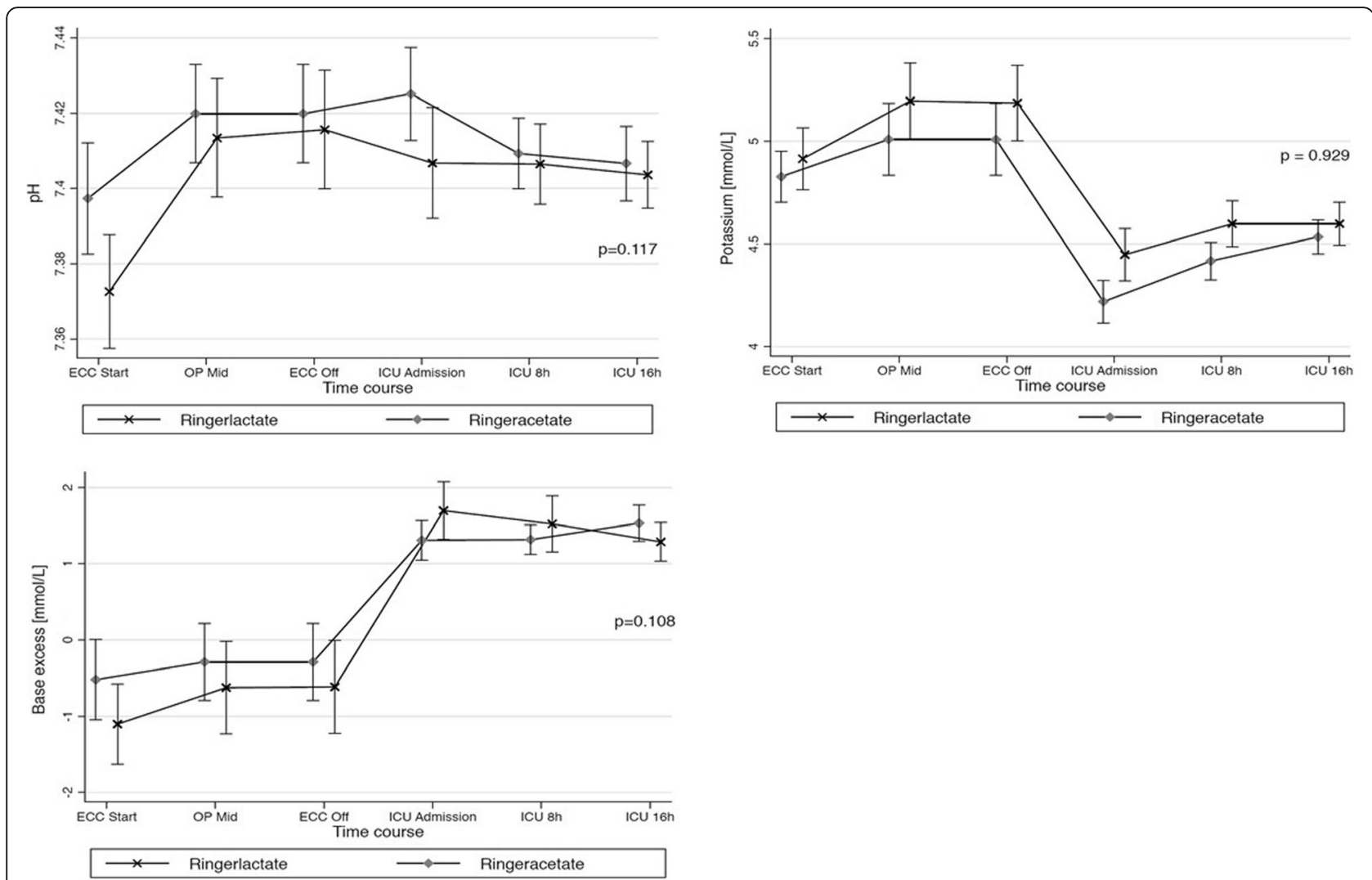

Fig. 3 Acid-base homeostasis - profile of Ringer's acetate and Ringer's lactate

and certainly need to be verified in a larger cohort before any definitive conclusions can be drawn.

Acetate and lactate are both weak acids that are converted into bicarbonate [31]. Lactate can be utilized by multiple pathways and is unlikely to produce acute changes in acid-base balance [37]. In contrast, acetate-buffered solutions may produce metabolic alkalosis due to rapid production of bicarbonate from acetate [13, 15, 38, 39].

However, a recent systematic review of studies comparing acetate-buffered solution to other crystalloids found that major increases in bicarbonate with acetatebuffered solutions were rarely observed [31]. Our study shows that even in patients undergoing cardiac surgery who receive large quantities of intravenous fluid within a short time period, the use of an acetate-buffered infusion solution did not result in a difference in metabolic alkalosis or alkalemia between the study groups.

Postoperative arrhythmias were recorded significantly more often in patients in the RL group than in patients in the RA group. Electrolyte blood concentrations were similar. Potential explanations are the differences in case mix, more frequent use of epinephrine in the RL group, and/or pre-existing but not documented differences in atrial geometry; however, this needs to be investigated further.
In our study cohort, $7.4 \%$ of the patients suffered from new postoperative neurological deficit. Cardiac valve procedures per se are a known risk factor for postoperative neurologic deficits in patients undergoing cardiac surgery [40]. In addition, the high proportion of patients that received an aortic or composite-graft procedure, the advanced age, and the high incidence of perioperative arrhythmia, all of which are well-known risk factors for perioperative strokes, might explain the proportion of $6.1 \%$ in our study population suffered from postoperative new stroke [40, 41].

The results of this study show that RA appears to be a feasible alternative to RL for perioperative fluid resuscitation in the critically ill, even when large quantities are needed. This could have implications for clinical practice.

The limitations of our study are its single-center design and the exclusion of patients with more severe cardiac and renal impairment. The former were excluded due to the higher need for perioperative inopressors in this population as a result of the underlying cardiac disease; that latter were excluded because patients with severe kidney dysfunction have an impaired ability to react to changes in acid-base homeostasis. Another limitation might arise from the fact that patients only received the study fluid until hemodynamic stabilization and not until ICU discharge. However, in our ICU, we give maintenance fluid after 
Table 3 Postoperative outcomes

\begin{tabular}{|c|c|c|c|}
\hline Characteristics & Ringer's acetate $(n=75)$ & Ringer's lactate $(n=73)$ & $p$ value* \\
\hline Occurrence of arrhythmia, $n$ (\%) & $24(32.0)$ & $39(53.4)$ & 0.008 \\
\hline Acute kidney injury, $n(\%)^{\#}$ & $11(14.7)$ & $10(13.7)$ & 0.866 \\
\hline Risk & 10 & 8 & 0.901 \\
\hline Injury & 1 & 1 & \\
\hline Failure & 0 & 1 & \\
\hline New neurological deficit, med (IQR) & $4(5.3)$ & $7(9.6)$ & 0.324 \\
\hline Critical illness polyneuropathy & 0 & 1 & \\
\hline Ischemic stroke & 4 & 5 & \\
\hline Peripheral nerve lesion & 0 & 1 & \\
\hline Coronary angiography, n (\%) & $2(2.7)$ & $5(6.9)$ & 0.272 \\
\hline Postoperative drainage output & $950(550-1200)$ & $1000(560-1320)$ & 0.415 \\
\hline Received blood product transfusion, $n(\%)$ & $24(32.0)$ & $19(26.0)$ & 0.424 \\
\hline Postoperative infection, n (\%) & $4(5.3)$ & $3(4.1)$ & 1.000 \\
\hline Other complications, $n$ (\%) & $8(10.7)$ & $4(5.5)$ & 0.368 \\
\hline Delirium & 1 & 0 & \\
\hline Pneumothorax & 2 & 0 & \\
\hline Significant pleural effusion & 2 & 1 & \\
\hline Skin rash & 1 & 1 & \\
\hline Transient hypoxemia & 2 & 2 & \\
\hline Surgical re-exploration needed, $n$ (\%) & $2(2.7)$ & $6(8.2)$ & 0.166 \\
\hline Need for postoperative mechanical circulatory support, $n(\%)$ & $0(0.0)$ & $2(2.7)^{+}$ & 0.242 \\
\hline \multicolumn{4}{|l|}{ Length of stay [days], med (IQR) } \\
\hline ICU & $0.9(0.7-0.9)$ & $0.9(0.8-0.9)$ & 0.494 \\
\hline IMC & $0.0(0.0-0.0)$ & $0.0(0.0-1.0)$ & 0.362 \\
\hline Hospital & $9.0(8.0-12.0)$ & $9.0(8.0-10.2)$ & 0.425 \\
\hline In-hospital mortality & 0 & 0 & \\
\hline
\end{tabular}

\#According to the RIFLE criteria

*Wilcoxon rank sum test for continuous and Fisher's exact test for categorical variables between the Ringer's acetate and Ringer's lactate study groups

${ }^{+}$One patient arrived with IABP from the OR, and one patient needed veno-arterial ECMO support in ICU

hemodynamic stabilization/extubation mainly for potassium substitution to prevent arrhythmia, and the amount is generally negligible. Further limitations arise from the imbalanced distribution of ascending aortic procedures between the groups, from the exclusion of patients undergoing only isolated CABG surgery, and due to the limited sample size. In addition, our study was designed as a pragmatic trial comparing the two solutions in the context of both groups receiving usual care. We cannot address the possible specific hemodynamic effects (e.g., vasodilatation) of either solution.

Further confirmatory studies are certainly warranted in the future.

\section{Conclusion}

In this study, in patients undergoing cardiac valve surgery, hemodynamic profiles and inopressor requirements were similar in patients receiving Ringer's lactate and Ringer's acetate for perioperative fluid resuscitation. Between- group differences in metabolic alkalosis commonly associated with larger loads of acetate infusion were not observed in this study. In this trial, Ringer's acetate solution appears to be an acceptable alternative to Ringer's lactate solution for perioperative fluid resuscitation in cardiac surgery. Our results need to be verified in a larger cohort, however.

\section{Additional file}

Additional file 1: Table S1. Primary and secondary endpoints-anesthesia versus ICU. (DOCX 15 kb)

\section{Abbreviations}

ICU: Intensive care unit; MAP: Mean arterial pressure; OR: Operating room; RA: Ringer's acetate; RL: Ringer's lactate; SOP: Standard operating procedures 


\section{Acknowledgements}

We thank Dr. Patricia Stoecklin for her support and Mrs. Jeannie Wurz for the language editing.

\section{Funding}

No external funding was received for this study.

\section{Availability of data and materials}

The datasets generated during and/or analyzed during the current study are available from the corresponding author on reasonable request.

\section{Authors' contributions}

CAP designed the strategy, wrote the protocol, organized the study, conducted the study, obtained the informed consent, evaluated and checked the data, and wrote the first draft. LF evaluated and checked the data for completion and correctness. MM checked and analyzed the data and revised the manuscript for important intellectual content. BE designed the strategy, revised the protocol, participated in the intraoperative conduct of the study, and revised the first draft for important intellectual content. HJJ designed the strategy and revised the manuscript for important intellectual content. BZ and JP conducted the study and revised the manuscript for important intellectual content. LE, JT, and SJ designed the strategy and revised the manuscript for important intellectual content. All authors read and approved the final manuscript.

\section{Ethics approval and consent to participate}

The study was approved by the ethics committee of the Canton of Berne.

\section{Consent for publication}

All authors give their consent for publication.

\section{Competing interests}

The authors declare that they have no competing interests.

\section{Publisher's Note}

Springer Nature remains neutral with regard to jurisdictional claims in published maps and institutional affiliations.

\section{Author details}

'Department of Intensive Care Medicine, Inselspital, Bern University Hospital, University of Bern, Freiburgstrasse 10, 3010 Bern, Switzerland. ${ }^{2}$ Institute of Health Economics and Clinical Epidemiology, University Hospital of Cologne, Cologne, Germany. ${ }^{3}$ Department of Emergency Medicine, Inselspital, Bern University Hospital, University of Bern, Bern, Switzerland. ${ }^{4}$ Department of Anaesthesiology and Pain Medicine, Inselspital, Bern University Hospital, University of Bern, Bern, Switzerland. ${ }^{5}$ Department of Cardiovascular Surgery, Inselspital, Bern University Hospital, University of Bern, Bern, Switzerland.

\section{Received: 14 August 2018 Accepted: 8 April 2019}

\section{Published online: 06 May 2019}

\section{References}

1. Challand C, Struthers R, Sneyd JR, Erasmus PD, Mellor N, Hosie KB, Minto G. Randomized controlled trial of intraoperative goal-directed fluid therapy in aerobically fit and unfit patients having major colorectal surgery. $\mathrm{Br} J$ Anaesth. 2012;108(1):53-62.

2. Magder S, Potter BJ, Varennes BD, Doucette S, Fergusson D. Fluids after cardiac surgery: a pilot study of the use of colloids versus crystalloids. Crit Care Med. 2010;38(11):2117-24

3. Schumacher J, Klotz K-F. Fluid therapy in cardiac surgery patients. Appl Cardiopulm Pathophysiol. 2009;13(1):138-42

4. Kramer A, Zygun D, Hawes H, Easton P, Ferland A. Pulse pressure variation predicts fluid responsiveness following coronary artery bypass surgery. Chest. 2004;126(5):1563-8.

5. Suzuki S, Woinarski NC, Lipcsey M, Candal CL, Schneider AG, Glassford NJ, Eastwood GM, Bellomo R. Pulse pressure variation-guided fluid therapy after cardiac surgery: a pilot before-and-after trial. J Crit Care. 2014;29(6):992-6.

6. Sponholz C, Schelenz C, Reinhart K, Schirmer U, Stehr SN. Catecholamine and volume therapy for cardiac surgery in Germany--results from a postal survey. PLoS One. 2014;9(8):e103996.
7. Verheij J, van Lingen A, Raijmakers PG, Rijnsburger ER, Veerman DP, Wisselink W, Girbes AR, Groeneveld AB. Effect of fluid loading with saline or colloids on pulmonary permeability, oedema and lung injury score after cardiac and major vascular surgery. Br J Anaesth. 2006;96(1):21-30.

8. Jacob M, Fellahi JL, Chappell D, Kurz A. The impact of hydroxyethyl starches in cardiac surgery: a meta-analysis. Crit Care. 2014;18(6):656.

9. Bayer O, Schwarzkopf D, Doenst T, Cook D, Kabisch B, Schelenz C, Bauer M, Riedemann NC, Sakr Y, Kohl M, et al. Perioperative fluid therapy with tetrastarch and gelatin in cardiac surgery--a prospective sequential analysis*. Crit Care Med. 2013;41(11):2532-42.

10. Hans GA, Ledoux D, Roediger L, Hubert MB, Koch JN, Senard M. The effect of intraoperative 6\% balanced hydroxyethyl starch (130/0.4) during cardiac surgery on transfusion requirements. J Cardiothorac Vasc Anesth. 2015;29(2):328-32.

11. Pfortmueller C, Funk GC, Potura E, Reiterer C, Luf F, Kabon B, Druml W, Fleischmann $\mathrm{E}$, Lindner $\mathrm{G}$. Acetate-buffered crystalloid infusate versus infusion of $0.9 \%$ saline and hemodynamic stability in patients undergoing renal transplantation: prospective, randomized, controlled trial. Wien Klin Wochenschr. 2017;129(17-18):598-604. https://doi.org/10.1007/s00508-0171180-4. [Epub 2017 Mar 2]

12. Pfortmueller CA, Funk GC, Reiterer C, Schrott A, Zotti O, Kabon B, Fleischmann E, Lindner G. Normal saline versus a balanced crystalloid for goal-directed perioperative fluid therapy in major abdominal surgery: a double-blind randomised controlled study. Br J Anaesth. 2018;120(2):274-83.

13. Kuze $S$, Ito $Y$, Miyahara $T$. Expiration of radioactive carbon dioxide by rats after administration of isotopic lactate and acetate. Acta Medica Biologica. 1986;34:93-102.

14. Chang-Seng L, Lowenstein J. Metabolic control of the circulation: effects of acetate and pyruvate. J Clin Investig. 1978;62:1029-38.

15. Knowles SE, Jarrett IG, Filsell OH, Ballard FJ. Production and utilization of acetate in mammals. Biochem J. 1974;142(2):401-11.

16. Nitenberg A, Huyghebaert MF, Blanchet F, Amiel C. Analysis of increased myocardial contractility during sodium acetate infusion in humans. Kidney Int. 1984;26(5):744-51.

17. Suokas A, Kupari M, Heikkila J, Lindros K, Ylikahri R. Acute cardiovascular and metabolic effects of acetate in men. Alcohol Clin Exp Res. 1988;12(1):52-8.

18. Doucet JJ, Hall RI. Limited resuscitation with hypertonic saline, hypertonic sodium acetate, and lactated Ringer's solutions in a model of uncontrolled hemorrhage from a vascular injury. J Trauma. 1999;47(5):956-63.

19. Uusaro A, Ruokonen E, Takala J. Splanchnic oxygen transport after cardiac surgery: evidence for inadequate tissue perfusion after stabilization of hemodynamics. Intensive Care Med. 1996;22(1):26-33.

20. Jakob SM, Ruokonen E, Takala J. Assessment of the adequacy of systemic and regional perfusion after cardiac surgery. Br J Anaesth. 2000;84(5):571-7.

21. Takala J, Dellinger RP, Koskinen K, St Andre A, Read M, Levy M, Jakob SM, Mello PV, Friolet R, Ruokonen E. Development and simultaneous application of multiple care protocols in critical care: a multicenter feasibility study. Intensive Care Med. 2008;34(8):1401-10

22. Yelland LN, Sullivan TR, Voysey M, Lee KJ, Cook JA, Forbes AB. Applying the intention-to-treat principle in practice: guidance on handling randomisation errors. Clin Trials. 2015;12(4):418-23.

23. McHugh ML. The chi-square test of independence. Biochem Med. 2013;23(2):143-9.

24. Potura E, Lindner G, Biesenbach P, Funk GC, Reiterer C, Kabon B, Schwarz C, Druml W, Fleischmann E. An acetate-buffered balanced crystalloid versus 0 . $9 \%$ saline in patients with end-stage renal disease undergoing cadaveric renal transplantation: a prospective randomized controlled trial. Anesth Analg. 2015;120(1):123-9.

25. Iseki K, Onoyama K, Maeda T, Shimamatsu K, Harada A, Fujimi S, Omae T. Comparison of hemodynamics induced by conventional acetate hemodialysis, bicarbonate hemodialysis and ultrafiltration. Clin Nephrol. 1980;14(6):294-8.

26. Mansell MA, Nunan TO, Laker MF, Boon NA, Wing AJ. Incidence and significance of rising blood acetate levels during hemodialysis. Clin Nephrol. 1979;12(1):22-5.

27. Holbert RD, Pearson JE, Gonzalez FM. Effect of sodium acetate infusion on renal function in the dog. Arch Int Pharmacodyn Ther. 1976;219(2):211-22.

28. Kirkendol PL, Starrs J, Gonzalez FM. The effects of acetate, lactate, succinate and gluconate on plasma pH and electrolytes in dogs. Trans Am Soc Artif Intern Organs. 1980;26:323-7.

29. Liang CS, Lowenstein JM. Metabolic control of the circulation. Effects of acetate and pyruvate. J Clin Invest. 1978;62(5):1029-38. 
30. Kveim M, Nesbakken R. Acetate metabolizing capacity in man. J Oslo City Hosp. 1980;30:101-4.

31. Pfortmueller CA, Fleischmann E. Acetate-buffered crystalloid fluids: current knowledge, a systematic review. J Crit Care. 2016;35:96-104.

32. Conahan ST, Dupre A, Giaimo ME, Fowler CA, Torres CS, Miller HI. Resuscitation fluid composition and myocardial performance during burn shock. Circ Shock. 1987;23(1):37-49.

33. Pfortmueller CA, Uehlinger D, von Haehling S, Schefold JC. Serum chloride levels in critical illness-the hidden story. Intensive Care Med Exp. 2018;6(1):10,

34. Kellum JA, Song M, Venkataraman R. Effects of hyperchloremic acidosis on arterial pressure and circulating inflammatory molecules in experimental sepsis. Chest. 2004;125(1):243-8

35. Chowdhury AH, Cox EF, Francis ST, Lobo DN. A randomized, controlled, double blind crossover study on the effects of 1-L infusions of $6 \%$ hydroxyethyl starch suspended in $0.9 \%$ saline Noluven) and a balanced solution (Plasma Volume Redibag) on blood volume, renal blood flow velocity, and renal cortical tissue perfusion in healthy volunteers. Ann Surg. 2014;259(5):881-7.

36. Chowdhury AH, Cox EF, Francis ST, Lobo DN. A randomized, controlled, double-blind crossover study on the effects of 2-L infusions of $0.9 \%$ saline and plasma-lyte(R) 148 on renal blood flow velocity and renal cortical tissue perfusion in healthy volunteers. Ann Surg. 2012;256(1):18-24.

37. Ferguson BS, Rogatzki MJ, Goodwin ML, Kane DA, Rightmire Z, Gladden LB. Lactate metabolism: historical context, prior misinterpretations, and current understanding. Eur J Appl Physiol. 2018;118(4):691-728.

38. Rohrig R, Wegewitz C, Lendemans S, Petrat F, de Groot $\mathrm{H}$. Superiority of acetate compared with lactate in a rodent model of severe hemorrhagic shock. J Surg Res. 2014;186(1):338-45.

39. Gille J, Klezcewski B, Malcharek M, Raff T, Mogk M, Sablotzki A, Taha H. Safety of resuscitation with Ringer's acetate solution in severe burn (VolTRAB)--an observational trial. Burns. 2014;40(5):871-80.

40. Cropsey C, Kennedy J, Han J, Pandharipande P. Cognitive dysfunction, delirium, and stroke in cardiac surgery patients. Semin Cardiothorac Vasc Anesth. 2015;19(4):309-17.

41. Tokuda Y, Narita Y, Fujimoto K, Mutsuga M, Terazawa S, Ito H, Uchida W, Usui A. Neurologic deficit following aortic arch replacement: the influence of the aortic atherosclerosis. Ann Thorac Surg. 2019;4975(19)30128-6. https://doi.org/10.1016/j.athoracsur.2019.01.004. [Epub ahead of print]

Ready to submit your research? Choose BMC and benefit from:

- fast, convenient online submission

- thorough peer review by experienced researchers in your field

- rapid publication on acceptance

- support for research data, including large and complex data types

- gold Open Access which fosters wider collaboration and increased citations

- maximum visibility for your research: over $100 \mathrm{M}$ website views per year

At $\mathrm{BMC}$, research is always in progress.

Learn more biomedcentral.com/submissions 